\title{
EDUCAÇÃO DO CAMPO E CURRÍCULO: UM ESTUDO DAS PROPOSTAS PEDAGÓGICAS DE ESCOLAS DO CAMPO DA REGIÃO DE DOURADOS/MS
}

\author{
Rural Education and Curriculum: a Study of the Pedagogical Proposals of Rural \\ Schools in the Region of Dourados/MS
}

\author{
Osmar Luís Nascimento Gotardi ${ }^{1}$ \\ Dario Xavier Pires ${ }^{2}$
}

\begin{abstract}
Resumo: A Educação do Campo tem ocupado espaço nas pesquisas da área de ensino, o que pode ser justificado em partes pela relevância que as comunidades campesinas vêm adquirindo na sociedade nos últimos anos. Porém, o cenário da educação escolar no contexto do campo ainda é caracterizado por desigualdades e desarticulações, apresentando-se como desafiador aos atores que compõem a comunidade escolar. Diante disso, socializou-se, neste artigo, que é o recorte de um trabalho de doutoramento em ensino de ciências, o estudo de aspectos inerentes à Educação do Campo, compreendendo suas especificidades e correlacionando-as às propostas pedagógicas de três escolas situadas na porção sul do estado de Mato Grosso do Sul. Com o objetivo de desvelar o que se contempla (ou não) no projeto pedagógico escolar acerca do currículo da escola do campo, desenvolveu-se uma análise qualitativa por meio de pesquisa bibliográfica e documental. No âmbito teórico, pesquisou-se sobre o contexto histórico e a legislação a respeito da Educação do Campo no Brasil e no aspecto da análise documental consultou-se o projeto pedagógico de cada escola e os seus referenciais curriculares estaduais. Após a análise, compreendeu-se que as propostas abarcam princípios e finalidades do funcionamento escolar que convergem com a ideia de uma educação emancipadora no campo, contudo, evidenciou-se pouca robustez em relação à abordagem de aspectos peculiares da Educação do Campo e do currículo escolar do campo, indicando que ainda são muitos os desafios para que os anseios e projetos da Educação do Campo sejam materializados no cotidiano escolar.
\end{abstract}

Palavras-chave: Currículo. Educação do Campo. Projeto Político-Pedagógico.

Abstract: Rural Education has occupied space in research in the area of education, which can be justified in part by the relevance that peasant communities have acquired in society in recent years. However, the school education scenario in the rural context is still characterized by inequalities and disarticulations, presenting itself as a challenge to the people that make up the school community. Therefore, in this article, which is the clipping of a doctoral dissertation in science teaching, the study of aspects inherent to Rural Education, understanding its specificities and correlating them to the pedagogical proposals of three schools located in the southern, became socialized. from the state of Mato Grosso do Sul. With the objective of unveiling what is contemplated (or not) in the school pedagogical project about the curriculum

\footnotetext{
${ }^{1}$ Doutorando no Programa de Pós-Graduação em Ensino de Ciências da Universidade Federal de Mato Grosso do Sul (UFMS) e Professor de Química no Instituto Federal do Paraná (IFPR). Orcid: https://orcid.org/0000-00025743-8199. E-mail: olngotardi@gmail.com.

${ }^{2}$ Doutor em Ciências da Saúde pela Universidade de Brasília (UnB) e Professor titular no Instituto de Química e no Programa de Pós-Graduação em Ensino de Ciências da Universidade Federal de Mato Grosso do Sul (UFMS). Orcid: https://orcid.org/0000-0002-7235-2369. E-mail: daxpires@yahoo.com.br.
} 
of the country school, a qualitative analysis was developed through bibliographical and documentary research. In the theoretical scope, research was done on the historical context and legislation regarding Rural Education in Brazil and in the aspect of documentary analysis, the pedagogical project of each school and its state curricular references were verified. After the analysis, it was understood that the proposals encompass principles and purposes of school functioning that converge with the idea of an emancipatory education in the countryside. However, there was little robustness in relation to the approach of peculiar aspects of Rural Education and the school curriculum from the countryside, indicating that there are still many challenges for the desires and projects of Rural Education to be materialized in the school routine.

Keywords: Curriculum. Rural Education. Political-Pedagogical Project.

\section{Introdução}

A Educação do Campo é um tema que tem conquistado espaço nos estudos concernentes à área de ensino, o que pode ser justificado pela relevância que as comunidades campesinas vêm adquirindo no meio social, saindo de uma posição marginalizada em vários âmbitos e, sobretudo, pelo esforço crescente que tem ocorrido para o asseguramento do acesso democrático a uma educação pública de qualidade (LANÇA; FERNANDES, 2020).

Apesar disso, Lança e Fernandes (2020) expõem que ainda hoje o panorama da educação escolar no contexto do campo é caracterizado por desigualdades e desarticulações, com um número não muito expressivo de experiências locais bem-sucedidas, de maneira que o cenário permanece marcado por desafios e pela necessidade de mais ações no sentido da universalização da oferta de uma educação que atenda às reais necessidades dos sujeitos do campo.

Nessa perspectiva, compreende-se ser fundamental que as instituições escolares atuantes no ambiente do campo tenham um projeto pedagógico coerente com a realidade vivenciada pela comunidade escolar, oportunizando aos povos campesinos condições de acesso e permanência ao itinerário educacional.

Considerando o exposto, buscou-se, neste artigo, apresentar alguns aspectos característicos da Educação do Campo, explicitando suas especificidades e correlacionando-as às propostas pedagógicas de três escolas do campo situadas na região da Grande Dourados, na porção sul do estado de Mato Grosso do Sul. Assim, procurou-se desvelar o que se estabelece (ou não) no projeto pedagógico escolar sobre o currículo da escola do campo, entendido como balizador das ações pedagógicas no ambiente escolar.

Para isso, o percurso metodológico ancorou-se numa análise qualitativa, por meio de pesquisa bibliográfica e análise documental. No âmbito teórico, pesquisou-se acerca do contexto histórico em que se insere a Educação do Campo e a legislação pertinente, considerados como elementos fundamentais para a compreensão do tema em estudo. No aspecto da coleta e análise de dados documentais, fez-se a consulta ao projeto pedagógico de cada escola investigada, uma vez que este é o principal documento orientador das instituições de educação, e aos referenciais curriculares estaduais por elas utilizados.

Entende-se que as principais contribuições desta pesquisa remetem à propiciação de reflexões acerca das peculiaridades que envolvem a Educação do Campo e o currículo da escola 
do campo, articulando-o aos princípios e finalidades que permeiam (ou deveriam permear) a proposta pedagógica desse tipo de instituição escolar.

\section{Educação do Campo: contexto histórico e características}

Camacho (2014) elenca três premissas importantes no que concerne ao contexto em que se constrói a Educação do Campo. A primeira diz respeito à reivindicação dos movimentos camponeses por uma educação de qualidade no campo, uma vez que a falta de políticas públicas para com os povos do campo refletiu-se em sua exclusão social durante muito tempo; a segunda se refere à reivindicação por uma educação que fosse construída juntamente com os sujeitos do campo, que fosse uma educação deles, alinhada à sua realidade, substituindo, dessa maneira, a descontextualizada educação rural à qual foram historicamente submetidos; e a terceira premissa é a de que a Educação do Campo se baliza por uma proposta emancipatória, à medida que representa um instrumento de resistência do campesinato à agricultura capitalista (CAMACHO, 2014).

Segundo Batista (1995), a realidade educacional dos residentes do campo foi marcada historicamente pela existência de uma grande quantidade de analfabetos, compondo um cenário em que o estudo dos campesinos limitava-se aos anos iniciais do ensino fundamental. Com relação a essa situação, Camacho (2014) expõe que a falta de políticas públicas para atender às necessidades educacionais dos povos do campo foi um dos fatores que contribuiu para a existência de um número considerável de analfabetos no campo.

No Brasil, a ideologia das classes dominantes, formadas pelas oligarquias agrárias que imperavam desde o Brasil colonial, sustentava o discurso de que o camponês não precisava aprender a ler e a escrever, a partir do argumento de que a própria natureza do trabalho camponês não exigia qualquer formação escolar (CAMACHO, 2014). Essa manutenção do status quo pelas elites dominantes, caracterizada pela negação do direito à educação para os sujeitos do campo ou mesmo pela educação voltada à submissão, pode ser evidenciada desde o período colonial com os missionários católicos, quando a educação foi pensada para os indígenas de forma a domesticá-los, facilitando sua escravização (CAMACHO, 2014).

Segundo Amorim e Sousa (2017), as origens da base educacional oferecida no campo, por meio da denominada educação rural, remontam a 1889, período da Proclamação da República, em que a instituição de uma educação atrelada ao ideário republicano objetivava "modernizar" a sociedade brasileira por meio da universalização da educação. Para tal, o governo fez com que os fazendeiros abrissem escolas em suas fazendas (SOUZA, 2014), sustentando uma educação balizada pelo pensamento latifundista empresarial e assistencialista, com o controle político sobre o meio rural e os sujeitos que viviam nele (FERNANDES; MOLINA, 2004).

Matos e Rocha (2020) expõem que, no advento da República, o desenvolvimento político, econômico e social do Brasil esteve atrelado ao processo de urbanização, de modo que a sociedade brasileira passou a atentar-se aos problemas do meio rural, dado o movimento migratório fortemente ocorrido por volta dos anos de 1910 e 1920. Conforme Fonseca (1985), foi nessa época que as elites começaram a realizar ações efetivas concernentes à educação rural na tentativa de reduzir a migração campo-cidade.

Nesse cenário, surgiu o movimento ruralista, engenhado pela oligarquia rural, com o objetivo de conter o trabalhador no campo, pois o êxodo rural passou a ser visto como foco de problemas sociais e, portanto, como ameaça às populações urbanas (MATOS; ROCHA, 2020). Para Matos e Rocha (2020), esse movimento ruralista se define por sua face político-ideológica 


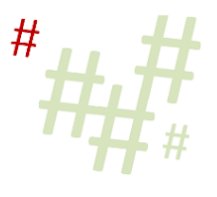

mascarada pela questão educacional, em que há um compromisso com a manutenção do status quo por meio da retenção do camponês às suas raízes e da garantia à qualificação do trabalhador do campo de acordo com as demandas do mercado.

Fonseca (1985) aponta que no seio desse movimento surgiu o chamado "ruralismo pedagógico", pautado na defesa de uma escola que "condissesse" com a realidade do camponês e "exaltasse" a vida e o trabalho no campo; por outro lado, alinhada a uma instrução de conteúdos que aperfeiçoariam o sujeito campesino, sem criar nele a expectativa de mudança de classe social. Para Silva et al. (2019), foi nessa perspectiva que a educação rural assumiu seu viés ideológico, fundamentando-se pelo não-reconhecimento do campo em sua diversidade, por meio de uma formação construída para o povo do campo, e não pensada por e com eles.

De acordo com Molina e Antunes-Rocha (2014), o período de 1940 a 1970 foi marcado por uma espécie de silenciamento no que tange às políticas públicas e às produções acadêmicas referentes à educação escolar no meio rural. Nesse contexto, configurou-se um cenário de precariedade física, administrativa e pedagógica das escolas rurais, ao mesmo tempo que implementavam-se as políticas agrícolas "modernizadoras" no país, caracterizadas pela concentração de terras, pelo fornecimento de créditos para grandes empreendimentos e pela mecanização nas atividades agropecuaristas (MOLINA; ANTUNES-ROCHA, 2014).

Com o alavancamento da chamada "modernização agrícola", o objetivo da educação rural, que era o de manter o campesinato "fixo" na terra e, simultaneamente, conter o aumento das lutas e organizações camponesas, passou a ser o de expropriar os camponeses de suas bases fundiárias, a fim de implantar no campo os projetos agrícolas do grande capital (AMORIM; SOUSA, 2017). Nessa perspectiva, Silvério e Isobe (2020) apontam que a educação rural impulsionou a migração dos sujeitos do campo para a cidade, a partir da sinalização de que o destino dos trabalhadores rurais seria o ambiente urbano e da ênfase na qualificação técnica e preparação de mão de obra para as indústrias.

Nesse contexto, Arroyo, Caldart e Molina (2004) explicitam que entre os anos de 1930 e 1980 duas tendências permearam as ações pedagógicas das escolas rurais, sendo elas a tendência ruralista e a tendência urbanizadora. A primeira voltava-se à formação dos sujeitos apenas para o campo, de forma a minimizar o êxodo rural; já a segunda, direcionava-se a formar o indivíduo para atuar na cidade, desconsiderando um ensino diferenciado que atendesse às especificidades de cada contexto escolar (ARROYO; CALDART; MOLINA, 2004).

Diante do exposto, evidencia-se que a educação rural foi marcada pela difusão da ideologia dominante sobre os sujeitos do campo. Para Camacho (2014), a educação rural envolveu uma escola adestradora, na qual os camponeses foram representados ideologicamente como pessoas ignorantes e manipuláveis, representações tais aceitas por eles mesmos. Camacho (2014) aponta ainda que essa escola da educação rural, apesar de estar localizada no campo, não se configurava como uma escola do campo.

Conforme Souza (2017), a expressão "escola no campo" indica que a instituição está situada no campo, enquanto a expressão "escola do campo" remete à escola que se constrói com base nos princípios da Educação do Campo, assim reconhecendo o vínculo com os sujeitos do campo. Nessa perspectiva, Fernandes (2004) explica que uma escola que está no campo, mas não é do campo, representa um modelo pedagógico em conformidade com a tradição ruralista de dominação, enquanto a escola do campo referencia-se pelas experiências próprias dos povos campesinos.

Segundo Silvério e Isobe (2020), o movimento social pela Educação do Campo iniciouse em meados da segunda metade do século XX, por meio de organizações de lutas no campo, 


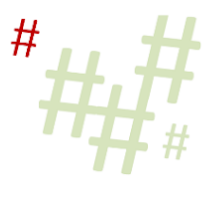

como o movimento das Ligas Camponesas na década de 1950, que reivindicava a reforma agrária e, nesse caminho, elaborava propostas educativas para o campo balizadas pelas experiências emergidas da própria vida campesina.

Caldart (2004) considera como principais elementos inerentes ao contexto de origem da Educação do Campo: a situação social das famílias camponesas trabalhadoras na época, caracterizada pela elevação da pobreza e da desigualdade e exclusão sociais; a barbárie causada pela implementação da agricultura capitalista; e a situação educacional caracterizada pela ausência de políticas públicas voltadas aos sujeitos do campo. Como reação a esse cenário, emergiram os movimentos de luta, em especial as lutas camponesas pela terra e pela Reforma Agrária, além do debate de um projeto de desenvolvimento social distinto do projeto do agronegócio (CALDART, 2004; CAMACHO, 2014).

A década de 1960 foi marcada por diversas lutas, projetos e debates políticos dos movimentos sociais, com propostas educacionais a fim de garantir a libertação e a autonomia dos sujeitos do campo (SILVÉRIO; ISOBE, 2020). Freitas (2011) cita exemplos como o Movimento de Educação de Base e o método de alfabetização de adultos proposto por Paulo Freire, que foram importantes para as ações dos movimentos, pois se propunham a preparar o indivíduo do campo para as reformas sociais e políticas. Silvério e Isobe (2020) frisam que esses movimentos enfrentaram dificuldades em razão do período da ditadura militar resultante do golpe de 1964, de forma que as organizações de lutas foram retomadas com maior força nos anos de 1980.

Silvério e Isobe (2020) destacam a fundação do Movimento dos Trabalhadores Rurais Sem Terra (MST) em 1984, um movimento que tem como uma de suas principais bandeiras a educação com respeito à diversidade e para todos. Uma das contribuições do MST foi a promoção, em 1997, do I Encontro Nacional de Educadores e Educadoras da Reforma Agrária (I ENERA), que contou com a parceria do Fundo Nacional da Infância (UNICEF), da Organização das Nações Unidas para Educação, Ciência e Cultura (UNESCO), da Conferência Nacional dos Bispos do Brasil (CNBB) e da Universidade de Brasília (UnB) (ARROYO; CALDART; MOLINA, 2004).

No I ENERA houve a reunião de cerca de 700 participantes na UnB, estando entre eles educadores infantis, alfabetizadores de jovens e adultos e professores de escolas de assentamentos e acampamentos (FREITAS, 2011; CAMACHO, 2014). No encontro, foi discutida e aprovada a proposta de um modelo de educação coletiva baseada em novas relações pessoais e valores humanos, por meio da qual se pudesse erradicar o analfabetismo nos acampamentos e assentamentos (FREITAS, 2011; CAMACHO, 2014).

A partir da parceria estabelecida no I ENERA, o MST promoveu, em 1998, no município goiano de Luziânia, a I Conferência Nacional por uma Educação Básica do Campo, na qual 1000 participantes, incluindo educadores da educação básica do meio rural, reuniramse para intercambiar experiências e discutir políticas públicas e projetos pedagógicos que primassem pela implementação de uma Educação Básica do Campo (FREITAS, 2011; CAMACHO, 2014).

Camacho (2014) expõe que nessa conferência foi defendida a necessidade de visualizarse o campo como parte integrante do mundo, e não somente como um "restolho" das cidades. Ferreira et al. (2020) explicitam que a partir desse momento o termo "rural" passou a ser substituído pela expressão "campo".

Em continuidade aos debates da conferência de 1998, aconteceu, em 2004, a II Conferência Nacional por uma Educação Básica do Campo, momento em que se reafirmou a 
necessidade da criação de políticas públicas de educação voltadas aos sujeitos do campo (FERREIRA et al., 2020).

Já no ano de 2015, ocorreu o II ENERA, no qual educadores, trabalhadores do campo, pais e estudantes reuniram-se para debater sobre diversos temas, tais como agronegócio, agroecologia, alimentação escolar e formação de professores (FERREIRA et al., 2020). Com relação a esse evento, Silva (2016) destaca o documento intitulado "Manifesto das Educadoras e dos Educadores da Reforma Agrária", no qual faz-se uma crítica ao capitalismo e manifestase uma série de compromissos de luta contra o capital, o neoliberalismo, o agronegócio, a privatização da educação, o preconceito, entre outros.

Para Camacho (2014), uma das razões que embasa a luta pela Educação do Campo é que esta não pode se definir por qualquer educação, mas precisa estar relacionada à realidade dos camponeses, de modo que eles tenham o direito de pensar o mundo a partir do lugar em que vivem, ou seja, do seu território.

Nesse sentido, Lança e Fernandes (2020) ressaltam que a Educação do Campo deve estar vinculada a um projeto de desenvolvimento do e no campo, pois este tipo de educação baliza-se por meio da observação e da experiência dos sujeitos do campo. Assim, a escola que segue a linha da Educação do Campo precisa convergir com a dinâmica da localidade onde se situa, considerando a história do povo campesino e o respeito ao seu modo de produção agrícola, bem como incorporando suas peculiaridades. É, pois, a partir disso, que devem emergir os conteúdos e debates a serem promovidos na escola (LANÇA; FERNANDES, 2020).

Em consonância com o exposto, Caldart (2004) frisa que os indivíduos do campo têm direito a uma educação no e do campo: é direito do povo ter uma educação que ocorra no espaço geográfico vivido (no campo) e que seja pensada com a participação dos sujeitos envolvidos e conforme suas necessidades (do campo).

\section{Escolas do campo: um panorama sobre a legislação}

Silva et al. (2019) destacam que a educação para os povos do campo encontrou espaço para o seu desenvolvimento a partir da publicação da Constituição de 1988 (BRASIL, 1988) e da Lei de Diretrizes e Bases da Educação Nacional (LDBEN) (BRASIL, 1996).

Segundo Matos e Rocha (2020), com a Constituição de 1988 (BRASIL, 1998) a educação das populações do campo passou a ser tratada como direito fundamental, quando proclamou-se no artigo 208, parágrafo primeiro, que "O acesso ao ensino obrigatório e gratuito é direito público subjetivo" (BRASIL, 1988, n. p.).

Ainda conforme os autores referidos, a LDB de 1996 (BRASIL, 1996) também expressa essa concepção de direito à educação, pois assegura a oferta de uma educação básica adequada às especificidades das pessoas que vivem no ambiente rural, por meio de currículo e de calendário escolar apropriados aos interesses e às necessidades dessa população (MATOS; ROCHA, 2020).

Nesta versão da LDB destaca-se o artigo 28, apresentado a seguir:

$\mathrm{Na}$ oferta da educação básica para a população rural, os sistemas de ensino promoverão as adaptações necessárias à sua adequação às peculiaridades da vida rural e de cada região, especificamente:

I Conteúdos curriculares e metodologias apropriadas às reais necessidades e interesses dos alunos da zona rural; 
II Organização escolar própria, incluindo a adequação do calendário escolar às fases do ciclo agrícola e as condições climáticas;

III Adequação à natureza do trabalho na zona rural. (BRASIL, 1996, n. p.).

Dias e Leonel (2018) salientam o avanço representado pela LDB e entendem que as adaptações e adequações previstas no artigo 28 devem ser desenvolvidas pela escola e por seus professores durante o planejamento pedagógico, de modo a valorizar o contexto dos estudantes.

Com relação ao conteúdo do artigo 28, Matos e Rocha (2020) consideram que há um reconhecimento da necessidade de diferenciação da Educação do Campo, porém, basicamente associam-se às peculiaridades campesinas à inserção dos estudantes no trabalho produtivo do campo, o que não se distingue da concepção de educação para o campo pensada historicamente.

Amorim e Sousa (2017), nessa mesma perspectiva, explicitam que a LDB, no que remete à Educação do Campo, representou a continuidade do modelo de educação rural já existente, uma vez que, mesmo assegurando aos camponeses o direito à educação, não garantiu a perspectiva de uma educação popular que fosse construída tendo como ponto de partida as demandas dos sujeitos do campo.

Da I Conferência Nacional por uma Educação Básica do Campo, de 1998, resultou a elaboração da Resolução 01/2002 do Conselho Nacional de Educação (CNE) e da Câmara de Educação Básica (CEB), a qual dispôs sobre as diretrizes operacionais para a educação básica nas escolas do campo, em que foram indicados preceitos e critérios a fim de orientar a organização das escolas do campo (SILVA et al., 2019).

Para Matos e Rocha (2020), a aprovação dessas diretrizes significou a oficialização da necessidade de uma educação que atendesse às peculiaridades das escolas do campo, apresentando avanços consideráveis quanto ao reconhecimento da identidade dessas escolas, conforme pode ser verificado no artigo $2^{\circ}$ do documento:

\begin{abstract}
A identidade da escola do campo é definida pela sua vinculação às questões inerentes à sua realidade, ancorando-se na temporalidade e saberes próprios dos estudantes, na memória coletiva que sinaliza futuros, na rede de ciência e tecnologia disponíveis na sociedade e nos movimentos sociais em defesa de projetos que associem as soluções exigidas por essas questões à qualidade social da vida coletiva no País. (BRASIL, 2002, p. 1).
\end{abstract}

Destaca-se também o artigo $10^{\circ}$ da Resolução 01/2002, no qual explicita-se que o projeto institucional das escolas do campo deve garantir a gestão democrática, compondo mecanismos que propiciem o estabelecimento de relações entre a escola, a comunidade, os movimentos sociais e os órgãos que normalizam o sistema de ensino (BRASIL, 2002).

Em 2008, foi aprovada a Resolução CNE/CEB $n^{\circ} 2$, que estabeleceu as diretrizes complementares, normas e princípios para o desenvolvimento de políticas públicas de atendimento da Educação Básica do Campo (BRASIL, 2008). Desta resolução destaca-se o artigo $1^{\circ}$, que expõe o seguinte:

A Educação do Campo compreende a Educação Básica em suas etapas de Educação Infantil, Ensino Fundamental, Ensino Médio e Educação Profissional Técnica de nível médio integrada com o Ensino Médio e destina-se ao atendimento às populações rurais em suas mais variadas formas de produção da vida - agricultores familiares, 
extrativistas, pescadores artesanais, ribeirinhos, assentados e acampados da Reforma Agrária, quilombolas, caiçaras, indígenas e outros. (BRASIL, 2008, p. 1).

Matos e Rocha (2020) enfatizam que o documento trata de forma precisa sobre a abrangência da Educação do Campo, conforme pode ser visto no trecho anterior. Para Silvério e Isobe (2020), o referido artigo carrega em seu conteúdo os diversos debates, as propostas, as ações e a concepção sobre a Educação do Campo, além de refletir um processo construído historicamente.

Outros pontos que destacam-se na Resolução CNE/CBE n $^{\circ} 2$ são o dever da Educação do Campo de atender jovens e adultos que não tiveram acesso aos estudos ou não os concluíram (parágrafo $4^{\circ}$ do artigo $1^{\circ}$ ); a necessidade da adoção de providências pelos sistemas de ensino para que as crianças e jovens portadores de necessidades especiais, e residentes no campo, tenham acesso à Educação Básica (parágrafo $5^{\circ}$ do artigo $1^{\circ}$ ); e o asseguramento do apoio pedagógico aos estudantes do campo bem como a infraestrutura apropriada e alinhada com a realidade local e as diversidades do povo campesino (artigo $7^{\circ}$ ) (BRASIL, 2008).

Em 2010, foi publicado o Decreto ${ }^{\circ}$ 7352, que dispõe sobre a política de educação do campo e o Programa Nacional de Educação na Reforma Agrária (PRONERA) (BRASIL, 2010). Neste documento, indica-se no parágrafo $1^{\circ}$ do artigo $1^{\circ}$ o entendimento de escola do campo como sendo aquela que está localizada em área rural ou a que encontra-se em área urbana, porém contempla predominantemente os sujeitos do campo (BRASIL, 2010).

Enfatiza-se o artigo $2^{\circ}$ do Decreto de 2010, o qual apresenta cinco princípios da Educação do Campo:

\footnotetext{
Art. $2^{\circ}$ São princípios da educação do campo:

I - respeito à diversidade do campo em seus aspectos sociais, culturais, ambientais, políticos, econômicos, de gênero, geracional e de raça e etnia;

II - incentivo à formulação de projetos político-pedagógicos específicos para as escolas do campo, estimulando o desenvolvimento das unidades escolares como espaços públicos de investigação e articulação de experiências e estudos direcionados para o desenvolvimento social, economicamente justo e ambientalmente sustentável, em articulação com o mundo do trabalho;

III - desenvolvimento de políticas de formação de profissionais da educação para o atendimento da especificidade das escolas do campo, considerando-se as condições concretas da produção e reprodução social da vida no campo;

IV - valorização da identidade da escola do campo por meio de projetos pedagógicos com conteúdos curriculares e metodologias adequadas às reais necessidades dos alunos do campo, bem como flexibilidade na organização escolar, incluindo adequação do calendário escolar às fases do ciclo agrícola e às condições climáticas; e V - controle social da qualidade da educação escolar, mediante a efetiva participação da comunidade e dos movimentos sociais do campo. (BRASIL, 2010, p. 1-2).
}

Destaca-se no artigo $2^{\circ}$ os princípios II e IV, nos quais explicita-se a importância da construção na escola do campo de um Projeto Político-Pedagógico (PPP) que esteja em consonância com o contexto no qual ela está inserida. A necessidade de um projeto pedagógico escolar que considere a escola como espaço para investigação e articulação de experiências, além da valorização da identidade da escola do campo por meio de um currículo que atenda as reais necessidades dos estudantes são princípios fundamentais para que a escola seja efetivamente uma "escola do campo" no sentido exposto por Souza (2017). 
É importante destacar também que no Decreto de 2010 há um enfoque sobre a relevância do preparo dos profissionais da educação para trabalhar no atendimento às peculiaridades da escola do campo, como observa-se no princípio III do artigo $2^{\circ}$, e mais especificamente no artigo $5^{\circ}$, sobre os processos de formação de professores, quando indica-se a possibilidade de metodologias de educação a distância para assegurar a formação apropriada de profissionais (parágrafo $1^{\circ}$ ); a possibilidade de formação docente concomitante à atuação profissional, com metodologias adequadas (parágrafo $2^{\circ}$ ); e a necessidade da incorporação dos processos de interação entre a cidade e o campo nos projetos político-pedagógicos de licenciaturas das instituições públicas de ensino superior (parágrafo $3^{\circ}$ ) (BRASIL, 2010).

Para Vighi (2015), a importância de uma adequação dos modelos de formação profissional para que se possa trabalhar eficazmente no contexto da Educação do Campo está ancorada na necessidade de se combater o descaso em relação à educação ao qual as populações rurais foram historicamente submetidas.

No âmbito da legislação estadual de Mato Grosso do Sul, tem-se a Deliberação do Conselho Estadual de Educaçã̃o (CEE/MS) n 7111 de 2003, que dispõe sobre o funcionamento da Educação Básica nas Escolas do Campo participantes do sistema de ensino do estado (MATO GROSSO DO SUL, 2003).

No artigo $2^{\circ}$ dessa Deliberação, traz-se a concepção de Educação Básica nas Escolas do Campo como aquela que se propõe a atender a população rural, balizando-se no respeito às diferenças e no direito à igualdade, bem como objetivando a oferta de uma educação de qualidade que leve em conta as especificidades dos sujeitos do campo (MATO GROSSO DO SUL, 2003). A relevância da inclusão dessas especificidades é evidenciada no parágrafo único do artigo $3^{\circ}$, em que aponta-se a necessidade da promoção de adaptações e adequações ao atendimento das peculiaridades que permeiam a vida rural (MATO GROSSO DO SUL, 2003).

Destaca-se o artigo $5^{\circ}$, que apresenta algumas finalidades da Educação Básica nas Escolas do Campo de Mato Grosso do Sul:

\footnotetext{
Art. 5. A Educação Básica nas Escolas do Campo deve ser ministrada com base nos seguintes fins e objetivos:

I. universalização do acesso;

II. erradicação do analfabetismo;

III. formação integral e apropriação pelo aluno do campo, dos conhecimentos historicamente acumulados;

IV. articulação do ensino com a produção e a preservação do meio ambiente;

V. formação do cidadão consciente dos seus direitos e deveres, com condições efetivas de intervenção para a transformação da realidade local e da sociedade;

VI. reconhecimento e valorização dos aspectos sócio-econômico-culturais do homem do campo, visando à sua fixação a terra. (MATO GROSSO DO SUL, 2003, p. 2).
}

São muito importantes os objetivos expostos no artigo $5^{\circ}$, pois expressam o compromisso pela oferta de uma educação para todos e que, de certa forma, busque reparar as desvantagens educacionais históricas vividas pelos povos do campo, ao mesmo tempo que primam pela formação de cidadãos conscientes de seus direitos e deveres e que saibam intervir na sociedade para transformar a sua realidade.

A Deliberação de 2003, em seu artigo 12, apresenta pontos relevantes sobre a construção do PPP da escola do campo, quando indica-se que as propostas pedagógicas dessas escolas devem contemplar a diversidade do campo em seus aspectos sociais, culturais, políticos, econômicos, étnicos, de gênero e de geração; a valorização dos conhecimentos historicamente 
acumulados nas atividades campesinas; e o reconhecimento da importância da preservação dos recursos naturais para garantir qualidade de vida e equilíbrio ambiental (MATO GROSSO DO SUL, 2003).

A Secretaria de Estado de Educação de Mato Grosso do Sul (SED/MS) tem publicado, ao longo dos anos, resoluções dispondo sobre a organização curricular e o regime escolar do Ensino Fundamental e do Ensino Médio nas escolas estaduais do campo. É o caso da Resolução SED/MS n 3796, que foi publicada em dezembro de 2020 (MATO GROSSO DO SUL, 2020).

Conforme o artigo $2^{\circ}$ dessa Resolução, as escolas do campo da Rede Estadual de Ensino de Mato Grosso do Sul têm dentre seus objetivos formar cidadãos críticos e preparados para continuar os estudos e inserir-se no mundo do trabalho; oportunizar acesso aos conhecimentos universais e específicos relacionados à realidade dos estudantes, incluindo-se as peculiaridades da realidade camponesa sul-mato-grossense; educar para o aprendizado de novas maneiras de desenvolvimento do meio rural, em consonância com o respeito à natureza; contribuir para que os moradores do campo melhorem sua qualidade de vida; e possibilitar que os estudantes, por meio do domínio da leitura, da escrita e do cálculo, ampliem sua capacidade de aprender (MATO GROSSO DO SUL, 2020).

\section{A Educação do Campo e os Projetos Político-Pedagógicos das escolas investigadas: discutindo o currículo}

Após abordar brevemente sobre o contexto histórico e os princípios norteadores da Educação do Campo e apresentar um panorama da legislação pertinente, procurou-se correlacionar esses elementos às especificidades e propósitos explicitados nos Projetos PolíticoPedagógicos de três escolas do campo do estado de Mato Grosso do Sul, na expectativa de desvelar o que se contempla (ou não) acerca do currículo, que é o que permeia as práticas pedagógicas em uma instituição escolar. Nessa perspectiva, faz-se necessário, primeiramente, dimensionar algumas nuances que fundamentam a concepção de currículo.

Faria (2020) considera que não é fácil definir currículo e recorre à descrição de sua gênese para uma compreensão mais ampla desse conceito. Segundo o autor, o significado de currículo estabeleceu-se ao longo da história, remetendo-se ao orador e cônsul romano Cícero, que foi o pioneiro na utilização do termo curriculum vitae, ainda hoje empregado para descrever o itinerário profissional de uma pessoa. Considerando-se que a raiz da palavra curriculum é a mesma para cursos e currere, o termo currículo pode ser entendido como o acúmulo das atividades realizadas ou também como a carreira de um estudante (FARIA, 2020).

Ao analisar o contexto histórico sobre o processo de formação do currículo, Faria (2020) conjectura que este foi construído por diversos quesitos interligados, os quais ainda hoje apresentam-se como influenciadores do currículo. Alguns dos quesitos citados por Faria (2020) são a estreita relação entre o caminho para a formação do indivíduo e a classe à qual pertence, a dependência desse caminho ao posicionamento político dos detentores do poder, a organização curricular disciplinar e a existência de crivo prévio sobre o que deve ser estudado.

Conforme Sacristán (2017), a concepção política, econômica e filosófica de quem detém o poder em uma sociedade materializa-se no currículo. Nesse sentido, Apple (2006) explica que é necessário que se tenha consciência de que o currículo não é um instrumento neutro, mas que carrega um viés ideológico e cultural. Assim, as ideias expostas por esses autores estão em consonância com um dos quesitos propostos por Faria (2020), que seria a dependência do caminho para a formação do sujeito ao posicionamento político de quem detém o poder. 
Com relação à organização curricular, Veiga (1995) chama a atenção para a necessidade da busca por novas maneiras de organização curricular, que sejam diferentes dos currículos que sistematizam o conhecimento escolar de forma hierárquica e fragmentada e que sustentam orientações conservadoras. Considera-se relevante a exposição desta autora, pois entende-se que para a formação de sujeitos críticos e atuantes na sociedade é preciso haver uma abordagem contextualizada dos conteúdos, o que muitas vezes é minimizado quando se tem o conhecimento escolar sistematizado de maneira hierarquizada e compartimentalizada.

Segundo Veiga (1995), o currículo é um instrumento de confronto entre o saber sistematizado, imprescindível para uma visão crítica da realidade, e o saber de classe, que o estudante representa e que resulta das formas de sobrevivência criadas pelas camadas populares. Para a autora, o trabalho educativo deve ter como ponto de partida o saber de classe.

Nesse contexto, Lima (2013) frisa que o currículo nas escolas do campo não pode ficar restrito aos conhecimentos científicos contidos nos livros didáticos, mas deve acolher os valores, as crenças e os saberes que os sujeitos do campo consideram relevantes para se abordar na escola. Assim, abarcando o desenvolvimento de conhecimentos e habilidades que propiciem às pessoas transformarem sua realidade sociocultural e econômica (LIMA, 2013).

Concorda-se com Braz et al. (2018) quando estes expõem sobre a necessidade de as escolas repensarem os currículos a fim de democratizá-los e ampliarem sua abertura ao diálogo com os diferentes saberes, indo além do contexto escolar e acadêmico.

Tendo em vista o abordado sobre o currículo escolar, buscou-se analisar a sua relação com os Projetos Político-Pedagógicos de algumas escolas do campo da região sul do estado de Mato Grosso do Sul. Optou-se por esse projeto uma vez que ele é o principal documento orientador das instituições escolares.

As três escolas estaduais pesquisadas estão situadas na região da Grande Dourados, na porção sul de Mato Grosso do Sul, sendo uma escola do campo (escola A) localizada num município e as outras duas escolas (escola B e escola C), também escolas do campo, localizadas em outro município da região. O PPP de cada instituição foi acessado na página virtual da SED/MS e os três documentos apresentam como data de sua última atualização o ano de 2020.

Numa breve caracterização da escola A tem-se que ela foi fundada em 1988 e está situada num distrito a cerca de $30 \mathrm{~km}$ da sede do município a que pertence. O contexto de construção da escola remonta ao final da década de 1970 com a mecanização da agricultura, o que provocou a diminuição do trabalho braçal no campo e o consequente êxodo rural durante os anos de 1980, acarretando o fechamento de escolas rurais e a elevação do número de estudantes nos distritos e cidades. Assim, a escola A foi edificada para atender os estudantes provenientes das escolas rurais antes existentes.

Essa escola oferta os anos finais do Ensino Fundamental e o Ensino Médio, funcionando nos turnos matutino e vespertino. Grande parte dos estudantes é oriunda da zona rural e muitos pertencem às famílias possuidoras de pequenas áreas rurais das quais tiram seu sustento, por meio da agricultura familiar, pela monocultura (soja, milho e mandioca) e pela manutenção de granjas (avicultura e suinocultura). Para chegar à escola, esses estudantes utilizam como transporte o ônibus escolar.

A escola B foi oficialmente criada em 1975, localizando-se num distrito que fica a cerca de $10 \mathrm{~km}$ da sede do município a que pertence. A construção da escola está ligada ao contexto do surgimento de um povoado que hoje constitui o distrito, em que os colonos ligados ao Núcleo Colonial de Dourados auxiliavam na abertura da terra e recebiam o protocolo de seu lote. 
Essa escola oferta os anos iniciais do Ensino Fundamental no turno matutino e os anos finais do Ensino Fundamental e o Ensino Médio no turno vespertino. Além dos estudantes residentes no distrito e seu entorno, a escola conta com estudantes oriundos da sede do município, os quais são levados à instituição pelos pais em veículo próprio, ou locomovem-se por meio de "caronas" dadas por professores que lá trabalham.

Os estudantes que residem no distrito e seu entorno provêm de famílias que se sustentam a partir de atividades diversas, destacando-se a agropecuária e a indústria. $\mathrm{Na}$ agricultura predominam as produções de cana-de-açúcar, soja, milho e mandioca, enquanto na pecuária tem maior expressão a produção leiteira. Quanto ao setor industrial, remete-se ao deslocamento diário de trabalhadores para uma usina de produção de álcool e uma fábrica de artigos esportivos presentes no município ou até mesmo para empresas de beneficiamento de alimentos situadas na região da Grande Dourados.

Quanto à escola C, tem-se que ela foi criada em 1975 e está situada num distrito a aproximadamente $18 \mathrm{~km}$ da sede municipal e a cerca de $8 \mathrm{~km}$ do distrito em que está localizada a escola $\mathrm{B}$, de maneira que os atos de criação de ambas as instituições remetem ao mesmo contexto temporal.

$\mathrm{Na}$ escola $\mathrm{C}$ ofertam-se os anos finais do Ensino Fundamental e o Ensino Médio no turno vespertino e a Educação de Jovens e Adultos (EJA) no noturno, sendo esta ofertada na modalidade de Projeto EJA Conectando Saberes Campo. O público dessa escola é composto em sua maioria por estudantes que residem na zona rural, provenientes de assentamentos, fazendas, chácaras e sítios, de modo que utilizam o ônibus escolar para chegar à instituição e, nesse processo, enfrentam distâncias consideráveis, além das dificuldades devido às condições climáticas em dias chuvosos e às más condições das estradas. É importante ressaltar que no perfil dos estudantes, além de pardos, brancos e negros, inserem-se pessoas indígenas. Do ponto de vista econômico, as famílias dos estudantes sustentam-se principalmente por atividades da agropecuária e da indústria, semelhantemente ao contexto vivido pela comunidade escolar da instituição B.

Assiste explicitar que no recorte da pesquisa para atender ao escopo desse artigo, delimitou-se a abordagem acerca da organização curricular da escola $\mathrm{C}$ ao Ensino Fundamental e Ensino Médio regulares.

A partir da breve descrição das características das escolas investigadas, buscou-se evidenciar no estudo dos PPPs os seguintes pontos: quais princípios essas escolas consideram quanto à sua missão, visão e valores enquanto instituição social; de que modo os fundamentos da Educação do Campo são expressos no projeto pedagógico escolar; e como se desvela a organização curricular nessas escolas, considerando-se que são credenciadas como instituições balizadas pela modalidade de Educação Básica do Campo.

Com relação às finalidades e princípios norteadores do funcionamento escolar, verificou-se, em geral, que as três escolas buscam proporcionar aos estudantes uma formação integral, na qual sejam desenvolvidas as capacidades intelectual, socioemocional, profissional e cidadã, assim auxiliando uma formação científica, cultural, ética, política e democrática dos sujeitos. Nos três PPPs analisados, enfatiza-se a missão da escola de contribuir para a formação de cidadãos críticos, capazes de agir com responsabilidade no meio social a fim de transformar positivamente sua realidade.

A preocupação com uma escola que seja inclusiva, com respeito ao próximo e às suas especificidades, é outro ponto em comum entre as escolas investigadas. Aponta-se a tolerância e a solidariedade ao ser humano como valores fundamentais para a formação integral dos 
estudantes. Isso pode ser evidenciado, por exemplo, no PPP da escola C, quando ressalta-se a importância do respeito às diferenças sociais, culturais e étnicas existentes entre os indivíduos.

Nos três PPPS evidenciou-se um olhar da comunidade escolar a uma formação que não seja estritamente acadêmica, mas que, além disso, contribua na formação para a cidadania, de forma que os sujeitos do campo sejam protagonistas de sua própria história. Nessa perspectiva, compreende-se que os princípios orientadores das atividades escolares apresentados nas propostas confluem para o desenvolvimento de uma educação de qualidade.

Conforme Molina e Antunes-Rocha (2014), um projeto de escola do campo deve, necessariamente, criar e estabelecer uma conexão entre educação e compromisso político, em que o universo cultural e as formas próprias de aprendizagem dos povos do campo sejam considerados nos processos de ensino-aprendizagem da escola, compondo, assim, um ambiente que forma os próprios camponeses como os protagonistas das lutas para as conquistas de seus direitos como cidadãos.

Ao averiguar-se a inserção das características balizadoras da Educação do Campo nos PPPs das escolas investigadas, notou-se que aquelas, nos projetos das escolas B e C, são abordadas com maior ênfase em relação ao projeto da escola A.

No PPP da escola A indicam-se algumas referências direcionadas à legislação concernente à Educação do Campo, como a Deliberação CEE/MS n 7111 de 2003 (MATO GROSSO DO SUL, 2003). Todavia, apesar de o projeto apresentar esse amparo legal em suas referências bibliográficas, pouco percebeu-se no corpo do texto a inserção de elementos orientadores específicos da Educação do Campo, de maneira que o documento não se diferencia muito de uma proposta pedagógica de escola urbana. Basicamente, faz-se alusão à participação dos estudantes no desenvolvimento de projetos escolares tais como Horta Agroecológica, Pomar, Jardinagem e Plantas Medicinais.

No PPP da escola B averiguou-se uma ênfase relevante dada aos princípios da Educação do Campo e suas relações com as atividades escolares. No documento explicita-se a proposta de uma educação voltada às reais necessidades dos povos do campo, considerando-se uma ação colaborativa entre escola e comunidade. Pauta-se numa educação pensada a partir da identidade dos sujeitos campesinos e dos valores que estes carregam na relação com o espaço que permeiam. Ao mesmo tempo, frisa-se que a escola não pode ficar restrita às questões do campo, mas deve propiciar um desenvolvimento educativo mais amplo, ofertando uma educação integral que possibilite aos estudantes o enfrentamento dos desafios do cotidiano e a contribuição com a transformação do meio em que vivem e da sociedade em geral.

Ressalta-se, no PPP dessa instituição (escola B), que a escola do campo deve balizar-se pelo respeito às decisões tomadas no coletivo, contribuindo para que os indivíduos tenham compromisso pessoal com as ações coletivas, sendo essa uma estratégia educacional integrada ao projeto de emancipação política, cultural, social e econômica das populações do campo. Nesse contexto, citam-se práticas de manutenção de limpeza implementadas na escola, tais como a poda de árvores e o plantio e colheita de frutas, verduras e legumes no espaço escolar, a fim de valorizar o ambiente local e reforçar nas pessoas o sentimento de pertencimento ao meio em que vivem.

Com relação à legislação, faz-se menção no projeto da escola B ao artigo 28 da LDB (BRASIL,1996), articulando-o à proposta de medidas de adequação da educação ao contexto do campo. Também se alude às Diretrizes Curriculares Nacionais da Educação Básica de 2013, do Ministério da Educação, destacando-se que o campo, mais do que um perímetro rural, é um 
espaço de possibilidades que potencializam a ligação do ser humano com a construção das condições de sua existência na sociedade.

No PPP da escola C indica-se a compreensão da Educação do Campo como uma política planejada pelo governo e pela sociedade civil, em que se propõe uma educação voltada às necessidades e especificidades das populações campesinas e que representa uma espécie de resgate da dívida histórica do país para com os sujeitos do campo que tiveram seu direito a uma educação de qualidade negada historicamente.

Apresenta-se nesse PPP o entendimento de que no processo de ensino-aprendizagem balizado pelos princípios da Educação do Campo busca-se resgatar os saberes da comunidade e relacioná-los com os conhecimentos científicos das diferentes áreas, sustentando-se a ideia de que os indivíduos do campo possuem condições de pensar uma educação baseada nas características peculiares da vida campesina, de modo que possam ser incluídos na sociedade como sujeitos transformadores.

No projeto dessa escola, abordam-se referências importantes no que tange à legislação da Educação do Campo, tais como a Constituição Federal de 1988 (BRASIL, 1988), quando expõe o compromisso do Estado e da sociedade em oportunizar a educação para todas as pessoas e considera a adequação da educação às peculiaridades culturais e regionais; a LDB de 1996 (BRASIL, 1996), que reconhece a diversidade sociocultural e o direito à igualdade, abrindo caminhos para a definição de diretrizes educacionais aos povos campesinos; a Deliberação CEE/MS de 2003 (MATO GROSSO DO SUL, 2003), que assegura que a educação nas escolas do campo de Mato Grosso do Sul seja pautada em concepções como o direito a uma formação humana, a proposição dos currículos em consonância com a realidade do campo e a valorização dos educadores do campo.

Fazendo uma análise geral, compreende-se que os fundamentos da Educação do Campo são abordados de forma mais tímida no PPP da escola A. Apesar da defesa na proposta de uma prática educativa para formar cidadãos críticos e conscientes dos seus direitos e deveres e que sejam agentes participativos e modificadores da realidade na qual estão inseridos, quase não se verificou a abordagem de aspectos peculiares da Educação do Campo. Já nas propostas das escolas B e C, averiguou-se que explicitam com maior enfoque acerca das questões do campo, discorrendo sobre a relevância de uma educação pensada a partir da identidade dos sujeitos do campo e de suas experiências, de maneira a atender as necessidades da população campesina.

Conforme Duarte, Oliveira e Domingos (2018), a educação do campo deve ser construída num processo coletivo, democrático e contextualizado com os indivíduos do campo e em consonância com suas demandas locais, de modo que a escola do campo seja caracterizada pelo reconhecimento do sujeito campesino no papel de legitimar a própria identidade. Assim, compreende-se que é de suma importância que esses aspectos balizem os projetos pedagógicos das escolas do campo, incluindo-se aí as escolas A, B e C.

As três escolas investigadas têm sua organização curricular orientada pelos referenciais curriculares estaduais, sendo o Currículo de Referência de Mato Grosso do Sul (2019) utilizado para o Ensino Fundamental e o Referencial Curricular da Rede Estadual de Ensino de Mato Grosso do Sul (2012) para o Ensino Médio. Ambos os referenciais são os mesmos utilizados nas escolas estaduais urbanas.

No Currículo de Referência de Mato Grosso do Sul (2019) propõe-se a ideia de um currículo contextualizado com a diversidade sul-mato-grossense e norteado por competências gerais trazidas pela Base Nacional Comum Curricular (BNCC) de 2017. Nesse contexto, o referencial destaca o compromisso com a educação integral, a fim de promover o 
desenvolvimento daquelas competências e assegurar que os estudantes aprendam. Apresentase a organização curricular por áreas e componentes curriculares que se dispõem em quadros contendo unidades temáticas, objetos de conhecimento, habilidades por série e ações didáticas. Discorre-se discretamente sobre a Educação do Campo, tratando-lhe como uma modalidade educacional e como política pensada pelo governo e sociedade civil a fim de propiciar uma educação de qualidade que foi historicamente negada aos sujeitos do campo.

No Referencial Curricular do Ensino Médio (2012) apresenta-se o currículo como um instrumento dimensionador do trabalho pedagógico a ser realizado pelos envolvidos no processo de ensino-aprendizagem, com o intento de organizar e consolidar o processo educativo. O referencial frisa que o currículo deve permitir o desenvolvimento pleno dos indivíduos no processo formativo, de forma que estes tenham acesso ao trabalho e ao exercício da cidadania. Apresenta-se a organização curricular por áreas e componentes curriculares que se dispõem em um rol de conteúdos sistematizados por períodos bimestrais, além das habilidades e competências. A Educação do Campo é explanada como sendo aquela compreendida no território dos sujeitos do campo e que objetiva, entre outros, erradicar o analfabetismo e formar integralmente o estudante campesino. Indica-se no documento que as escolas do campo, além da base nacional comum, trabalham na parte diversificada da matriz curricular com o eixo temático "Terra-Vida-Trabalho" (TVT).

Direcionado ao eixo TVT, tem-se o Referencial Curricular dos Eixos Temáticos TerraVida-Trabalho das Escolas do Campo da Rede Estadual de Ensino de Mato Grosso do Sul (2015), no qual evidencia-se que o eixo TVT deve permear toda a abordagem pedagógica, teórica e prática da formação discente e direciona-se para a estruturação de coletivos pedagógicos pelos professores a fim de realizar um trabalho coerente e interdisciplinar. Apresenta-se a organização curricular do eixo temático dispondo-se de um rol de conteúdos sistematizados por períodos bimestrais e acompanhados das competências e habilidades.

Com relação à legislação acerca da organização curricular, verificou-se nos PPPs analisados a menção a resoluções da SED/MS que em 2021 encontram-se revogadas. Assim, considera-se que as versões das propostas de 2020 precisam de atualização nesse aspecto. Para efeito de análise, utilizou-se neste artigo a Resolução vigente SED/MS nº 3.796 de 2020.

Na referida Resolução, descrevem-se as matrizes curriculares do Ensino Fundamental e do Ensino Médio organizadas por áreas de conhecimento e componentes curriculares, distribuídas entre a base nacional comum e a parte diversificada. O eixo TVT é apontado como componente curricular dos referidos níveis de ensino, destacando-se nos artigos 15 e 26 que a componente constitui ferramenta de construção e fortalecimento dos vínculos dos estudantes campesinos com a terra, buscando-se assim a integração dos sujeitos à realidade vivenciada.

No PPP da escola A são mencionados alguns documentos estaduais acerca da organização curricular nas escolas do campo, entretanto, não se verifica uma abordagem explícita sobre a concepção de currículo que fundamenta as atividades da escola. Também não observou-se explanação a respeito de aspectos inerentes ao currículo escolar integrado como a interdisciplinaridade, por exemplo. Basicamente, indica-se que, além da organização curricular por disciplinas, realizam-se projetos temáticos na instituição, abordando-se temas como horta agroecológica, dengue, leitura e relação família-escola, sendo este último voltado para as necessidades da comunidade escolar e promoção de sua melhoria. Não fica claro no PPP se esses projetos são demarcados por viés interdisciplinar.

No PPP da escola B defende-se um currículo permeado pelo desenvolvimento de metodologias que contribuam para a autonomia dos estudantes. Considera-se fundamental a valorização dos conhecimentos prévios dos discentes e a postura ativa destes na resolução de 
situações-problema com as quais deparam-se. Aponta-se o desenvolvimento de atividades interdisciplinares e multidisciplinares tais como aulas de campo e projetos temáticos, porém, não se esmiúça sobre esses trabalhos, sendo somente citados possíveis temas de projetos, dentre eles Educação Ambiental, Educação Alimentar e Nutricional, Cultura Digital, Cultura Sulmato-grossense e diversidade cultural.

A componente curricular TVT é enfatizada na proposta pedagógica da escola, sendo considerada como caminho de oportunidades aos estudantes e um efetivo "laboratório a céu aberto", uma vez que, por ser voltada à realidade local, envolve trabalhos tanto no espaço interno quanto externo à escola, implicando na participação e no diálogo com a comunidade.

$\mathrm{Na}$ proposta pedagógica da escola $\mathrm{C}$ ressalta-se o compromisso com a educação integral do estudante, por meio da promoção do desenvolvimento das competências gerais trazidas na BNCC de 2017, dentre elas: exercitar a empatia, solucionar problemas, saber trabalhar coletivamente e com respeito ao outro, ter autonomia para a tomada de decisão. Remete-se a um modelo pedagógico escolar balizado pela interdisciplinaridade e contextualização e centrado no estudante como sujeito de seu conhecimento. Defende-se que o estudante seja instrumentalizado cientificamente para que possa agir de forma consciente e responsável diante dos seus semelhantes e do mundo.

Para isso, indica-se no PPP o eixo temático TVT e as áreas do conhecimento contempladas na base comum como norteadores de uma organização curricular interdisciplinar, abordando conteúdos disciplinares pré-estabelecidos nos referenciais curriculares, além de outras atividades contribuidoras para a formação dos estudantes, como o trabalho em projetos. Reforça-se que as atividades pedagógicas devem partir da interdisciplinaridade, da contextualização e da transversalidade, sendo apontada a necessidade de inclusão de temáticas no currículo, tais como a História e Cultura Afro-Brasileira e Indígena, a Educação em Direitos Humanos e a Educação Ambiental.

Analisando os PPPs, verifica-se que a proposta da escola $\mathrm{C}$ é a que mais trata da necessidade de uma organização curricular balizada pela interdisciplinaridade e contextualização, porém, em nenhuma das propostas observou-se uma explanação sobre as concepções que a comunidade escolar tem a respeito desses aspectos.

As três escolas destacam a realização de projetos, apresentando-os como instrumentos que oportunizam o debate de temas contemporâneos no ambiente escolar e que, de certa forma, potencializam o desenvolvimento de práticas integradas. Apesar disso, inexiste uma abordagem sobre se e como a interdisciplinaridade é inserida no cotidiano das aulas, num ambiente em que a organização curricular está sistematizada pela compartimentalização em disciplinas. Diante desse cenário, reforça-se a defesa pela inserção efetiva de práticas interdisciplinares e contextualizadoras no currículo escolar, especialmente para as escolas do campo. Conforme Veiga (1995), é preciso que haja um currículo integrador, com a minimização da fragmentação do conhecimento, isto é, um currículo que seja integrado em um contexto amplo, de maneira que a visão do todo não seja perdida. Para Lança e Fernandes (2020), essa compreensão de currículo é fundamental numa escola do campo.

Para Lima (2013), o currículo da escola do campo precisa oportunizar aos estudantes a integração entre os conhecimentos científicos adquiridos pelas experiências vivenciadas na escola e os saberes populares provenientes da vivência de práticas sociais e culturais. Nesse sentido, Braz et al. (2018) entendem que é fundamental a reflexão pelos educadores acerca de como os conteúdos estão sendo abordados em sala de aula e o quanto estão sendo interligados e tendo sentido para os estudantes. Concorda-se com esses autores à medida que entende-se ser primordial que os professores das escolas do campo considerem, no processo de ensino- 
aprendizagem, a relevância de relacionar os conteúdos estudados à realidade dos estudantes campesinos, de forma que esses estudos possam fazer-lhes sentido.

Outro ponto de destaque nos PPPs remete à integração entre a componente TVT e as demais disciplinas, observando-se que nenhuma das propostas detalha acerca de como ocorre essa integração no cotidiano escolar. Assiste ressaltar que nos PPPs das escolas B e C alude-se ao eixo temático TVT e sua importância para atender as reais necessidades dos estudantes das escolas do campo, todavia não há um detalhamento em abordar sobre a referida integração. $\mathrm{O}$ que se considera fundamental, pois se compreende que os princípios da Educação do Campo devem permear toda a organização curricular da escola do campo, e não ficar sob o olhar apenas da componente curricular TVT.

Em consonância, destaca-se o artigo 12 da Resolução SED/MS no 3.796 de 2020, que faz alusão aos currículos do Ensino Fundamental e do Ensino Médio, nos quais aponta-se a obrigatoriedade de uma base comum e de uma base diversificada, ambas devendo ser planejadas, desenvolvidas e avaliadas como um todo integrado e não como dois blocos separados (MATO GROSSO DO SUL, 2020).

É importante explicitar o exposto no parágrafo único do artigo 12 (MATO GROSSO DO SUL, 2020), segundo o qual a articulação entre a base nacional comum e a parte diversificada do currículo propicia que os interesses de formação básica do cidadão estejam em sintonia com as necessidades dos estudantes e sua realidade social.

\section{Considerações finais}

No desenvolvimento desta pesquisa a respeito da Educação do Campo, compreendeuse que as discussões acerca de tal tema ainda são recentes e inserem-se na reflexão de um contexto histórico caracterizado pela negação de uma educação de qualidade aos sujeitos do campo. Nesse cenário, constatou-se a importância do desenvolvimento de políticas públicas educacionais eficazes para assegurar uma educação escolar do campo que respeite a identidade do indivíduo campesino e atenda às suas reais necessidades.

Ao sistematizar um panorama sobre a legislação brasileira no que tange à Educação do Campo, averiguou-se que essa educação escolar básica é garantida por lei aos sujeitos campesinos. Para as escolas do campo do estado de Mato Grosso do Sul, dentre as quais incluem-se as instituições escolares investigadas nesse trabalho, verificou-se que a Educação do Campo está bem assegurada e fundamentada legalmente, por meio de deliberações e resoluções elaboradas com base nas peculiaridades dos povos campesinos do estado.

No entanto, considera-se relevante a comparação e reflexão sobre o que se contempla na legislação e o que de fato se concretiza nas escolas do campo, de modo que os fundamentos da Educação do Campo não fiquem apenas no discurso. Não se espera, por exemplo, que o currículo de uma escola do campo, na prática, se equivalha à abordagem de conteúdos padronizados e pré-estabelecidos, sem considerar as especificidades da comunidade escolar.

No âmbito das propostas pedagógicas investigadas nesta pesquisa, percebeu-se que os três documentos abarcam princípios e finalidades do funcionamento escolar que convergem com a ideia de uma educação emancipadora no campo. Todavia, considerou-se que as especificidades da Educação do Campo são apresentadas de maneira tímida no PPP da escola A, o que indicia a compreensão de que ainda há muitos desafios para que os anseios e projetos da Educação do Campo sejam materializados. 
No que tange à organização curricular das escolas investigadas, a qual é estruturada conforme resolução da SED/MS e sistematiza-se por disciplinas distribuídas entre uma base comum e uma base diversificada, não observou-se ao longo das propostas uma explanação com detalhamentos sobre ações pedagógicas interdisciplinares entre o eixo TVT e as demais disciplinas, ou mesmo entre estas, no cotidiano das aulas.

Diante do exposto, concorda-se com Lança e Fernandes (2020), de que a efetivação de uma prática docente que potencialize o desenvolvimento da autonomia dos estudantes, e a existência de uma gestão escolar que se preocupe com a construção de um PPP ao mesmo tempo diferenciado e inclusivo, são algumas das ações importantes de serem realizadas nas escolas do campo. Assim, defende-se como fundamental a realização de processos formativos no cotidiano escolar, especialmente formações continuadas de professores, que possibilitem amplos debates e reflexões sobre a Educação do Campo e o currículo escolar.

\section{Referências}

AMORIM, F. C. L.; SOUSA, R. A. D. A educação do contexto da questão agrária brasileira e as políticas do estado para a educação no/do campo. Inter-Ação, Goiânia, v. 42, n. 2, p. 325346, maio/ago. 2017. Disponível em:

https://www.revistas.ufg.br/interacao/article/view/46073. Acesso em: 23 out. 2021.

APPLE, M. W. Ideologia e currículo. São Paulo: Brasiliense, 2006.

ARROYO, M. G.; CALDART, R. S.; MOLINA, M. C. Por uma educação do campo. Petrópolis: Vozes, 2004.

BATISTA, L. C. Cadernos de formação: uma contribuição à formação do professor de geografia e a sua atuação em zona rural. Aquidauana: UFMS, 1995.

BRASIL. [Constituição (1988)]. Constituição da República Federativa do Brasil de 1988. Brasília: Presidência da República, 1988. Disponível em:

http://www.planalto.gov.br/ccivil_03/Constituicao/Constituicao.htm. Acesso em: $11 \mathrm{fev}$. 2021.

BRASIL. Lei no 9.394, de 20 de dezembro de 1996. Estabelece as diretrizes e bases da educação nacional. Brasília: Presidência da República, 1996. Disponível em: http://www.planalto.gov.br/ccivil_03/Leis/L9394.htm. Acesso em: 11 fev. 2021.

BRASIL. Resolução CNE/CEB n $\mathbf{n}^{\mathbf{0}}$ 1, de 3 de abril de 2002. Institui diretrizes operacionais para a educação básica nas escolas do campo. Brasília: Câmara de Educação Básica, 2002. Disponível em:

http://portal.mec.gov.br/index.php?option=com_docman\&view=download\&alias=13800rceb001-02-pdf\&category_slug=agosto-2013-pdf\&Itemid=30192.

Acesso em: 12 fev. 2021.

BRASIL. Resolução CNE/CEB no 2, de 28 de abril de 2008. Estabelece diretrizes complementares, normas e princípios para o desenvolvimento de políticas públicas de atendimento da educação básica do campo. Brasília: Câmara de Educação Básica, 2008. Disponível em: http://portal.mec.gov.br/cne/arquivos/pdf/2008/rceb002_08.pdf. 
Acesso em: 12 fev. 2021.

BRASIL. Decreto $n^{0}$ 7.352, de 4 de novembro de 2010. Dispõe sobre a política de educação do campo e o Programa Nacional de Educação na Reforma Agrária - PRONERA. Brasília: Presidência da República, 2010. Disponível em: http://portal.mec.gov.br/docman/marco2012-pdf/10199-8-decreto-7352-de4-de-novembro-de-2010/file. Acesso em: 12 fev. 2021.

BRAZ, J. C. et al. Interdisciplinaridade, currículo e formação de professores no contexto da educação do campo. Revista Eletrônica Científica Ensino Interdisciplinar, Mossoró, v. 4, n. 12, p. 714-723, nov. 2018. Disponível em:

http://natal.uern.br/periodicos/index.php/RECEI/article/view/1722. Acesso em: 23 out. 2021.

CALDART, R. S. Elementos para construção do projeto político e pedagógico da educação do campo. Revista Trabalho Necessário, Niterói, v. 2, n. 2, p. 1-16, 2004. Disponível em: https://periodicos.uff.br/trabalhonecessario/article/view/3644. Acesso: 23 out. 2021.

CAMACHO, R. S. Paradigmas em disputa na educação do campo. 2014. Tese (Doutorado em Geografia) - Faculdade de Ciências e Tecnologia, Universidade Estadual Paulista, Presidente Prudente, 2014.

DIAS, F. F.; LEONEL, A. A. Escolas do campo: um olhar sobre a legislação e práticas implementadas no ensino de física. Revista Ensaio, Belo Horizonte, v. 20, p. 1-22, 2018. Disponível em: https://www.scielo.br/j/epec/a/NC7mPvWSLMqVrrf4HT6CPJR/?lang=pt. Acesso em: 23 out. 2021.

DUARTE, T. S.; OLIVEIRA, A. M.; DOMINGOS, D. A. A ressignificação curricular possibilitada por meio da temática dos agrotóxicos: um processo de compreensão do contexto para a educação do campo. Currículo sem Fronteiras, Campinas, v. 18, n. 2, p. 691-718, 2018. Disponível em: https://www.curriculosemfronteiras.org/vol18iss2articles/duarteoliveira-domingos.html. Acesso em: 23 out. 2021.

FARIA, A. G. V. A formação do professor de química para a atuação na Educação Profissional e Tecnológica: princípios pedagógicos para a formação do trabalhador. 2020. Tese (Doutorado em Ensino de Ciências) - Instituto de Física, Universidade Federal de Mato Grosso do Sul, Campo Grande, 2020.

FERNANDES, B. M. Diretrizes de uma caminhada. In: ARROYO, M. G; CALDART, R. S.; MOLINA, M. C. (org.). Por uma educação do campo. Petrópolis: Vozes, 2004. p. 133-145.

FERNANDES, B. M.; MOLINA, M. C. O campo da educação do campo. In: JESUS, S. M. S. A.; MOLINA, M. C. (org.). Contribuições para um projeto de educação no campo. Brasília: Articulação Nacional por uma Educação do Campo, 2004, p. 32-53.

FERREIRA, D. F. et al. Perspectivas na formação de professores (as) na educação do campo: reflexões a partir das escolas do campo. Revista Formação Docente, Belo Horizonte, v. 12, n. 1, p. 170-186, jan./jun. 2020. Disponível em: https://www.metodista.br/revistasizabela/index.php/fdc/article/view/1945. Acesso em: 23 out. 2021. 
FONSECA, M. T. L. A extensão rural no Brasil: um projeto educativo para o capital. São Paulo: Loyola, 1985.

FREITAS, H. C. A. Rumos da Educação do Campo. Em aberto, Brasília, v. 24, n. 85, p. 3549, abr. 2011. Disponível em:

http://rbep.inep.gov.br/ojs3/index.php/emaberto/article/view/3073. Acesso em: 23 out. 2021.

LANÇA, J. F.; FERNANDES, T. C. A educação do campo e suas especificidades: um estudo do projeto político pedagógico de uma escola do campo no município de Londrina-PR.

Revista Brasileira de Educação do Campo, Tocantinópolis, v. 5, p. 1-22, 2020. Disponível em: https://sistemas.uft.edu.br/periodicos/index.php/campo/article/view/9938. Acesso em: 23 out. 2021.

LIMA, E. S. Educação do campo, currículo e diversidades culturais. Espaço do currículo, João Pessoa, v. 6, n. 3, p. 608-619, set./dez. 2013. Disponível em:

https://periodicos.ufpb.br/index.php/rec/article/view/18998. Acesso em: 23 out. 2021.

MATO GROSSO DO SUL. Deliberação CEE n 7.111, de 16 de outubro de 2003. Dispõe sobre o funcionamento da educação básica nas escolas do campo, no Sistema Estadual de Ensino de Mato Grosso do Sul. Campo Grande: Conselho Estadual de Educação, [2003]. Disponível em: http://www.cee.ms.gov.br/wp-content/uploads/2015/08/del-7111.pdf. Acesso em: 12 fev. 2021.

MATO GROSSO DO SUL. Resolução SED no 3.796, de 2 de dezembro de 2020. Dispõe sobre a organização curricular e o regime escolar do ensino fundamental e do ensino médio nas escolas da Rede Estadual de Ensino de Mato Grosso do Sul [...], [2020]. Disponível em: http://aacpdappls.net.ms.gov.br/appls/legislacao/sed/legased.nsf/e3258672435f390e04257134 005057a1/757a064762899ab104258634006de537?OpenDocument.

Acesso em: 12 fev. 2021.

MATO GROSSO DO SUL. Currículo de referência de Mato Grosso do Sul: educação infantil e ensino fundamental. Campo Grande: SED, 2019.

MATO GROSSO DO SUL. Referencial curricular da rede estadual de ensino de Mato Grosso do Sul: ensino médio. Campo Grande: SED, 2012.

MATO GROSSO DO SUL. Referencial curricular dos eixos temáticos Terra-VidaTrabalho das escolas do campo da rede estadual de ensino de Mato Grosso do Sul: ensino fundamental e ensino médio. Campo Grande: SED, 2015.

MATOS, C. C.; ROCHA, G. O. R. O currículo da educação do campo no contexto das legislações nacionais. Revista Brasileira de Educação do Campo, Tocantinópolis, v. 5, p. 123, 2020. Disponível em:

https://sistemas.uft.edu.br/periodicos/index.php/campo/article/view/4582. Acesso em: 23 out. 2021.

MOLINA, M. C.; ANTUNES-ROCHA, M. I. Educação do campo: história, práticas e desafios no âmbito das políticas de formação de educadores - reflexões sobre o Pronera e o Procampo. Revista Reflexão e Ação, Santa Cruz do Sul, v. 22, n. 2, p. 220-253, jul./dez. 
2014. Disponível em: https://online.unisc.br/seer/index.php/reflex/article/view/5252. Acesso em: 23 out. 2021.

SACRISTÁN, J. G. O currículo: uma reflexão sobre a prática. Tradução: Ernani F. da Fonseca Rosa. 3. ed. Porto Alegre: Penso, 2017.

SILVA, F. N. S. et al. Educação do campo e ensino de ciências no Brasil: uma revisão dos últimos dez anos. Revista Brasileira de Ensino de Ciência e Tecnologia, Ponta Grossa, v. 12, n. 1, p. 221-239, jan./abr. 2019. Disponível em: https://periodicos.utfpr.edu.br/rbect/article/view/7547. Acesso em: 23 out. 2021.

SILVA, P. R. S. Trabalho e Educação do Campo: o MST e as escolas de ensino médio dos assentamentos de Reforma Agrária do Ceará. 2016. Dissertação (Mestrado em Educação) Faculdade de Educação, Universidade Federal do Ceará, Fortaleza, 2016.

SILVÉRIO, L. D.; ISOBE, R. M. R. Educação do campo em perspectiva: história, política pública e formação continuada de professores/as do ensino básico. Revista Brasileira de Educação do Campo, Tocantinópolis, v. 5, p. 1-23, 2020. Disponível em: https://sistemas.uft.edu.br/periodicos/index.php/campo/article/view/6894/16478. Acesso em: 23 out. 2021.

SOUZA, M. A. Escola pública no/do campo, formação de professores e projeto políticopedagógico: experiências no contexto do Programa Observatório da Educação. Formação Docente, Belo Horizonte, v. 9, n. 16, p. 27-48, 2017. Disponível em: https://revformacaodocente.com.br/index.php/rbpfp/article/view/160. Acesso em: 23 out. 2021.

SOUZA, M. M. Imperialismo e educação do campo. Araraquara: Cultura Acadêmica, 2014.

VEIGA, I. P. A. Projeto político pedagógico da escola: uma construção possível. Campinas: Papirus, 1995.

VIGHI, C. S. B. A. Formação docente: a educação do campo em foco. Formação Docente, Belo Horizonte, v. 7, n. 13, p. 115-132, ago./dez. 2015. Disponível em:

https://revformacaodocente.com.br/index.php/rbpfp/article/view/126. Acesso em: 23 out. 2021.

Recebido em abril de 2021.

Aprovado em outubro de 2021. 